\title{
COMENTARIO FILOLÓGICO DE UN EPÍGRAFE LATINO (CLE 960)
}

\author{
Leonor E. Molero Alcaraz
}

Texto ${ }^{1}$ :

Tu qui secura spatiarus mente uiator et nostri uoltus derigis inferieis, si quaeris quae sim, cinis en et tosta fauilla, ante obitus tristeis Heluia Prima fui.

5 Coniuge sum Cadmo fructa Scrateio concordesque pari uíximus ingenio.

Nunc data sum Diti longum mansura per aeum deducta et fatali igne et aqua Stygia.

Traducción:

Caminante, tú que paseas con intención apacible, y a mi sepultura vuelves un rostro curioso, si quieres saber quién soy — aquí me tienes, cenizas y consumido rescoldofui Helvia Prima antes del triste adiós.

Gocé de mi esposo Cadmo Escrateyo

y en concordia vivimos por una misma manera de pensar.

Ahora estoy entregada a Plutón el Rico, para quedarme a lo largo del tiempo que largo fluye, toda vez que me han bajado desde la pira inevitable, y atravesando el agua de la Éstige.

1 Seguimos la conocida edición de los CLE de F. Bücheler: Carmina Latina Epigraphica, (F. Bücheler - A. Riese - E. Lommatzsch, Anthologia Latina, II, 2, editio stereotypa, Amsterdam, 1964 (=Lipsiae, 1897). 


\section{Introducción.}

Antes de adentrarnos en el texto que precede, valgan algunas referencias a sus circunstancias materiales, y a otras características externas del mismo. Se trata de una inscripción funeraria hallada en Benevento, estudiada por Mommsen y otros especialistas ya a mediados del siglo pasado ${ }^{2}$. Aparece transcrita en $C I L$ IX 1837 y otros lugares, así como en distintas ediciones epigráficas ${ }^{3}$. Fue descubierta en aquella ciudad del suroeste de Italia, en la antigua región del Samnio, entre las piedras amontonadas para la edificación de una iglesia, y luego depositada en el Museo Nacional de Nápoles.

Se describe también en el CIL que está grabada con letras antiguas y claras, entre las que se encuentra la llamada $i$ long $a^{4}$, que una vez nota $i$ larga - uíximus (v. 6) -, y otra $i$ consonántica o doble $i$-Scrateio (v. 5) -; este uso gráfico, frecuente e indiscriminado - señalado en las ediciones modernas mediante un acento sobre la $i$-, se acompaña en la inscripción de otras letras longae como $T$ y $V^{5}$, no señaladas en aquélla.

Por un probable error de omisión, el lapicida no habría reproducido completo el original del verso 5, o bien pudo ya tratarse de un verso inconcluso cuando llegó a su cincel; sea como fuera, faltan algunas sílabas para la correcta escansión de ese hexámetro, sobre el que algunos autores propusieron reconstrucciones válidas ${ }^{6}$, pero no imprescindibles para la interpretación del verso, por lo cual no las hemos recogido en la traducción; sí sería recomendable incluir en las ediciones del texto un signo $<>$ de corrección por omisión, a fin de señalar que falta algo en el mismo ${ }^{7}$.

El epígrafe perteneció a la tumba de una mujer, Helvia Prima, cuya condición social más probable sería la de liberta, a juzgar por su segundo apelativo, y sobre todo por el nombre griego Cadmus de su marido. Con independencia de los condicionamientos reales de tipo cultural y económico, que no podemos averiguar con certeza, Helvia Prima es alguien que se procura una tumba particular,

2 Véanse referencias en $C I L$ IX, 1837 y I 1220. Estudios posteriores de los CLE son los de C. Weyman «Studien zu den Carmina Latina Epigraphica», Blaett. $f$. Gymnasialsch, XXXI, 1895, pp. 529-556 o J. A. Tolman, A Study of the Sepulchral Inscriptions in Bücheler's "Carmina Latina Epigraphica», Chicago, 1910; estudios más específicos, diversos trabajos de H. Armini, por ejemplo. «Symbolae epigraphicae», Eranos XXIV, 1926, pp. 56-70 y 123-128; Eranos XXVI, 1928, pp. 253-260; Eranos XXXI, 1933, pp. 31-52 y Eranos XXXIII, 1935, pp. 75-80, o bien F. Plessis, Épitaphes. Textes choisis et commentaires, París, 1905.

3 L. Rubio - V. Bejarano, Documenta ad linguae latinae historiam inlustrandam, (n: 130), Madrid, 1955; A. Degrassi, Inscriptiones latinae liberae reipublicae II (n985), Florencia, 1972; A. Ernout, Recueil de textes Latins archaïques (n. 98), París, 1973, etc.

4 M. Leumann, Lateinische Laut - und Formenlehre, (Lateinische Grammatik von Leumann Hofmann - Szantyr, erster Band), Neuausgabe 1977 der 1926-1928 in 5 Auflage, München, \& 13; M. Bassols de Climent, Fonética Latina, Madrid, 1973, \& 60.

5 eT, frucTa, daTa, DiTi, aeVm, deducTa, eT, STygia.

6 Ernout, op. c., p. 50: < dilecto $>$ fructa, Ritschl; < uixit dum $>$ fructa, Mommsen.

7 En las ediciones de Rubio-Bejarano y Ernout se señalan gráficamente los elementos métricos que faltan. 
con un epitafio que debió encargarse al menos a un versificador, cuando no a un poeta medianamente aceptable, quien compondría para la lápida sepulcral una breve tirada de dísticos elegíacos que, como después veremos, se acercan en cierta manera al modelo del epigrama funerario latino.

Bücheler sitúa este carmen en época cesariana — dato que concuerda con un hecho intrínseco de orden métrico, que igualmente analizaremos más adelante-, si bien Ernout acepta con dudas tal datación ${ }^{8}$.

El tratarse de un poema epigráfico es lo que nos lleva a intentar un comentario de texto sobre el mismo, para abordarlo con intención filológica en sus diferentes aspectos, no necesariamente reductibles a lo epigráfico o, como mucho, a lo lingüístico. Seguiremos para ello un orden de exposición ${ }^{9}$ en el que se estudiarán primeramente los elementos y recursos de expresión; a continuación el contenido que se sirve de dichos elementos, a la vez que les confiere un trasfondo comunicativo, y en último lugar propondremos una valoración crítica de esta inscripción, probablemente algo más que una simple pieza de museo, o texto escrito sin otras luces que las de servirnos de constatación de datos históricos, lingüísticos o culturales.

\section{Expresión.}

\subsection{Nivel gráfico-fonético y nivel métrico.}

Junto a otros rasgos ya mencionados, destacan en el plano de la escritura distintos procedimientos para representar $i$ larga:

- dígrafo ei para $i$ larga en inferieis (v. 2) - dat. pl. de inferiae, -arumy en tristeis (v. 4) - ac. pl. en -is dentro del giro preposicional ante obitus tristeis-. Desde el punto de vista métrico-prosódico, sólo se cuenta una vocal larga $i$, ya que ei tiene un valor meramente gráfico; en sus respectivos pentámetros, inferieis proporciona el semipié final del verso, y tristeis el quinto semipié ante cesura medial.

- i longa en uíximus (v. 6), mientras otras íes largas se representan a la manera clásica: qui (v. 1), nostri (v. 2), fui (v. 4), pari (v. 6), Diti (v. 7), fatali (v. 8).

También las grafías para la secuencia $u u$ muestran sus peculiares formas no clásicas ${ }^{10}$ en el ac. pl. uoltus (v. 2) y en el ac. en sintagma preposicional aeum (v. 7), ofreciendo distintas soluciones. Ya se sabe que la vocal breve originaria $o$ sufre un cambio de timbre en época histórica, y que normalmente evoluciona cerrándose en $u$; sin embargo, en cualquier posición de la palabra en que vaya precedida de $u$, se tiende a evitar los peligros de tal evolución, a saber el que ambas úes - la original y la que resulta de la evolución de $o$ breve- se confundan

8 Cf. nota 6 .

9 Para este orden de exposición hemos recogido algunas ideas del libro de M. Andueza, Comentario de textos latinos 1 (Catulo, Virgilio y Juvenal), Méjico, 1982.

10 S. Mariner, Inscripciones Hispanas en verso, Barcelona, 1952, pp. 27-28. 
en una sola articulación, como demuestran las grafías fonéticas del tipo aeum en el texto, resultado que es el que termina imponiéndose a lo largo del tiempo, si consideramos evoluciones romances como esp. río $<$ rium $<$ riuum. Para evitar tal confluencia y consiguiente eliminación, por reducción de los dos sonidos en uno solo, se produce a veces una especie de disimilación preventiva, y la lengua retrasa el oscurecimiento de $o$, o bien, si éste se produce siguiendo la tendencia general del cambio fonético de esta vocal, no se registra el cambio en la escritura durante bastante tiempo, manteniéndose hasta época virgiliana una grafía etimológica del tipo uoltus en el texto, similar a las de equos, sequontur, uiuont, etc. ${ }^{11}$.

Las pautas métrico-prosódicas del poema coinciden, grosso modo, con las clásicas, si bien debemos destacar dos peculiaridades importantes.

En el hexámetro incompleto al que antes aludíamos - verso 5-, contando con las correcciones propuestas, se produce una licencia por la cual no se efectúa el habitual alargamiento por posición de una vocal final seguida de palabra que comienza por más de una consonante - fructa Scrateío-. Esta licencia se produce ante secuencias fónicas $s p$-, $s t$-, $s c$-, $s q u$-, str-, scr-, donde el común denominador es la presencia de la llamada «s líquida»; en esta posición, la silbante debió tener una articulación debilitada, realizándose como una especie de aspiración, en una secuencia consonántica aparentemente doble o triple, pero donde a efectos de pronunciación no se realizaría sino una consonante simple, o un grupo muta cum liquida, precedidos de un simple soplo aspirado — quizá similar al de determinadas pronunciaciones de la $h^{12}$ - , por lo que, en la pronunciación real, no se dan las condiciones exigidas para un alargamiento por posición. Desde otro orden de cosas, justifica Müller ${ }^{13}$ el fenómeno en cuestión por la importancia decisiva del quinto pie en el verso heroico, dada su naturaleza propiamente dactílica, aunque, por otra parte, aquél no es ajeno a otras posiciones del hexámetro ni a otros metros donde la breve comporta la tesis. Esta licencia la utilizan Lucilio, Lucrecio, e incluso Horacio y Propercio, en lugares registrados en la obra de Müller, pero termina por caer en desuso en épocas posteriores.

En segundo lugar, se dan en el pentámetro del cuarto dístico - verso 8- lo que Bücheler califica de catullianae licentiae: unido a tres elisiones casi seguidas en el verso - deducta et fatali igne et...-, se da el hecho de que la cesura medial caiga en interior de palabra, tras la segunda sílaba de fatali, lo que es posible por la elisión - más bien fusión- de la vocal final $i$ ante la vocal inicial del mismo timbre de la palabra siguiente. No es en absoluto un hecho aislado, ya que como norma teórica admitían los griegos en el primer miembro del verso elegíaco la anulación de una sílaba en contacto con cesura, y Catulo adapta en ocasiones esta práctica, que también se da aisladamente en Propercio ${ }^{14}$.

11 Bassols, op. c., \&\& 112 y 133.

12 Bassols, op. c., \& 245.

13 L. Müller, De re metrica poetarum latinorum praeter Plautum et Terentium libri septem, Hildesheim, 1967 (=Leipzig, 1894), lib. V, p. 386.

14 Cat. LXVIII, 10: muneraque et Musarum hinc petis et Veneris. 
Esta última licencia quizás pueda servir como dato interno para fechar el poema en una época no anterior a Catulo: si el autor anónimo del epígrafe imita al veronés, no puede haber compuesto su titulus antes del año 70 a. JC., ni quizás acercarse a la época de la poesía clásica, donde tal uso métrico es ya inhabitual. De cualquier manera, esto no viene sino a corroborar la tesis de Bücheler de que se trata de un carmen de época cesariana o, según este factor métrico, catuliana.

\subsection{Nivel morfosintáctico.}

Es relevante en el primer hexámetro la forma verbal spatiarus, considerada dialectal frente a spatiaris, la forma clásica equivalente ${ }^{15}$. La desinencia que distingue a la primera forma de la segunda puede ser antigua, es decir, ${ }^{*}-S O-S>-r u s$, con una hipercaracterización de esta desinencia indoeuropea mediante una $-s$, analógica a la de 2 a persona sg. de la voz activa. Por el contrario, la desinencia clásica -ris procede de una refección sobre -re $<*$-se, producida en época histórica, sobre esta desinencia que en indoeuropeo alternaba con ${ }^{*}$-so, hipercaracterizada en latín según acabamos de decir. Junto a la forma histórica tipo legere $<*$ legese, de 2 . persona sg. medio-pasiva, presente de indicativo y presente de imperativo, se crea una alternativa legeris que proporciona una forma plenamente caracterizada como indicativo, siguiéndose el modelo de la oposición de la voz activa, legis (indicativo) / lege (imperativo), con lo que se obtiene una oposición paralela legeris (indicativo) / legere (imperativo), aunque sin dejar de usarse ésta última como forma de indicativo, si bien en regresión. La evolución habitual de $e$ en sílaba final cerrada, que pasa a $i$, y la importancia de la especial pronunciación de $-s$ en final absoluto de palabra, como marca morfológica, llevarían al asentamiento fonético-morfológico de la nueva desinencia -ris, obtenida en época histórica sin haberse producido necesariamente una formación antigua ${ }_{\text {-se-s, }}$, paralela a ${ }^{*}-S O-S$, sino un procedimiento de equivalencias morfológicas entre las voces activa y pasiva.

La desinencia -rus aparece esporádicamente en Catón, $A g r ., 157.8$, donde se encuentra la forma experirus - al igual que en alguna lectura de Catulo 21,6 ${ }^{16}$ - , y en otras formas epigráficas: utarus CIL I 1267, figarus CIL IV 2082, patiarus CIL VI 10736. Esta desinencia podría verse simplemente como una alternativa morfológica a -re, similar a la que se da en la flexión nominal consonántica para el gen. sg., donde se encuentran genitivos epigráficos en -us, -os, para nombres de divinidad, tipo Venerus ${ }^{17}$ que responden a la alternancia de desinencia nominal de genitivo *-es / * -os.

\section{Prop. 1, 5, 32: quaerere: non impune illa rogata uenit; // \\ 3, 22, 10: Herculis Antaeique, Hesperidumque choros. II}

L. Nougaret, Traité de métrique latine classique, $3^{\mathrm{e}}$ ed., Paris, 1963, \& 144.

15 A. Ernout, Morphologie historique du latin, $3^{\mathrm{e}}$ éd., París, 1974, \& 182.

16 Leumann, \& 397, 2, Vetter, «Zur lateinischen Grammatik», WSt. 24, 1962, pp. 534 y ss.

17 Leumann, \& 355, p. 435. 
Otra forma destacable desde el punto de vista morfológico es el ac. pl. tristeis (v. 4), donde ya hemos dicho que el dígrafo ei representa una $i$ larga, al igual que en otros ejemplos epigráficos de época republicana ${ }^{18}$. Este acusativo plural originario en $-\bar{l} s<{ }^{*}-i$-ns se conserva en los adjetivos, junto al ac. sg. en -im de determinados sustantivos y junto al ablativo sg. en $-i$. Desde el último tercio del siglo II a. JC. va haciéndose frecuente la confusión entre el nominativo y el acusativo plural de dichos temas, desplazando normalmente la desinencia -es de nominativo a la desinencia -is de acusativo, de la misma manera que -em, (-e), desinencias de los temas consonánticos, sustituyen a -im, (-i) en numerosos casos, excepto en algunas terminologías. El ac. pl. en $-\bar{l} \bar{s}$, y la consiguiente oposición formal para el nominativo y el acusativo plural de estos temas, se mantienen en general a lo largo de época republicana, y posteriormente en los sustantivos que conservan las desinencias - $i m$, $-i$, por una parte, y como elemento arcaizante, desde Virgilio, en los adjetivos en $-i$ y en los participios en $-n t$, si bien la forma clásica usual es la desinencia -es. El ejemplo que comentamos no ha de entenderse, pues, como un arcaísmo morfológico, dada la época en que se sitúa la inscripción, frente a los ejemplos posteriores de ac. pl. en -īs, en los que los adjetivos correspondientes funcionan aportando un rasgo de estilo desde el plano morfológico, a saber, un colorido o sabor de antiguo ${ }^{19}$.

Se observan también los siguientes hechos sintácticos: a) en la flexión nominal.-

- plurales poéticos ${ }^{20}$ : uoltus (v. 2) y obitus (v. 4) se usan en plural pese a referirse a conceptos singulares, quizás con el fin de lograr determinadas matizaciones expresivas.

El plural sintáctico de uoltus parece reforzar su especial significación abstracta de «rasgos o expresiones del rostro que exteriorizan un estado anímico», expresando el plural determinadas partes de la cara que pueden reflejar una sensación interior, que en un contexto donde aparece la construcción si quaeris quae sim bien puede ser una impresión de curiosidad o sorpresa; de ahí el valor concreto aportado por el plural y que recogemos en la traducción «...vuelves un rostro curioso».

El plural de obitus es igualmente expresivo, y probablemente se deba no sólo a exigencias métricas - para evitar una sinalefa y elisión de semipié fuerte ante cesura medial, tipo obitum tristem Heluia -, sino a la intención de enfatizar la acción de despedirse de la vida, con las connotaciones de tristeza o amargura que comporta, reforzadas mediante la atribución tristeis. Sin embargo, la presencia entre ambos plurales poéticos del plurale tantum del verso 2, inferieis, pudo arrastrar mecánicamente la elección de los otros dos plurales.

18 Ejemplos tomados de la edición de A. Degrassi: aedeis $(464,12)$; auctorateis $(662,6)$; fineis (517, 3 y 28); omneis $(454,3 ; 517,43$ y 589,2), todos ellos acusativos; como inferieis, cf. liberteis (785, $1)$, etc.

19 Leumann, \& 357 c, p. 439-440.

20 M. Bassols, Sintaxis histórica de la lengua latina, I, Barcelona, 1945, \& 21, 4. 
- dativo de dirección inferieis: esta construcción sintáctica también supone un uso propio de la lengua de la poesía ${ }^{21}$, en cuanto para indicar el punto de convergencia de la acción verbal desplaza a un sintagma preposicional in / ad + ac. más propio de la lengua hablada.

El dativo de dirección es un uso antiguo de la sintaxis nominal latina, según J. Marouzeau, que se revitaliza en la poesía postclásica reforzado por factores coadyuvantes - construcciones de dativo régimen con verbos de movimiento, helenismos sintácticos en los que el dativo aparece con este valor local-; sin embargo, se limita en esta época a palabras como caelo, Olympo, Auerno, Oceano y similares. Junto a la ligera anticipación que supone este ejemplo del poema, también se da una particularidad de orden léxico, en cuanto se trata de una palabra de la lengua religiosa, en lo referido al ritual del culto a los muertos. Rubio, como otros autores ${ }^{22}$, sostiene un uso propio en el llamado dativo de dirección, dado que se puede extraer el rasgo «interés» en ejemplos como el que nos ocupa: inferieis, con su valor específico en este contexto, representa de alguna manera la parte visible de todo lo que queda de una persona - el sepulcro, los objetos que lo adornaran, la urna o sarcófago, los mismos restos humanos-; es como si todo esto representara a la persona que llama la atención del posible lector que pase, y en esta identificación por desplazamiento de lo continente a lo contenido cabe entender el interés de la persona representada en la acción uoltus derigere. b) En la flexión pronominal.-

Señala Ernout en su comentario de esta inscripción que nostri... inferieis (v. 2) equivale a nostris...inferiis; hay que entender, en consecuencia, una sustitución del adjetivo posesivo por el genitivo del pronombre personal correspondiente. En ambas construcciones, más frecuente la de adjetivo posesivo que la de pronombre en genitivo, debe destacarse un valor «objetivo» común ${ }^{23}$ : «mis ofrendas / sepultura» son las «ofrendas (hechas) a mi».

Junto a esto, se da una polarización del género femenino en el interrogativo quae (v. 3), en vez del más indeterminado quis; se anticipa así que se trata de una mujer, cuyo nombre aparece en el verso siguiente con la misma función del pronombre interrogativo, esto es, la de predicado nominal, con un verbo fui en primera persona.

c) En la flexión verbal.-

Respecto a la categoría de persona, la 1. y la 2. aparecen con una función equiparada en el texto: se reserva el protagonismo de la acción a la 2 a hasta la mitad del tercer verso, donde se produce el relevo de la 1.. Es esto lo esperado en un texto donde el entramado básico de la comunicación consiste en una inter-

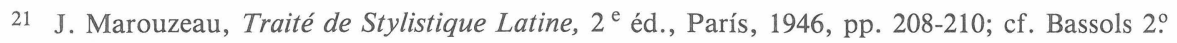
op. c., \& 149.

22 L. Rubio, Introducción a la sintaxis estructural del latin, 2. ed., Barcelona, 1984, pp. 150-151; cf. Marouzeau, nota 21.

23 M. Bassols, Sintaxis Latina, I, Madrid, 1976, \& 180; A. Ernout - F. Thomas, Syntaxe Latine, $2^{\text {e }}$ éd., París, 1972, \& 208. 
pelación de un tú — uiator, en aposición al pronombre personal es, según esto, un vocativo ${ }^{24}$ - , por parte de un yo que expone su mensaje referido a sí mismo.

En cuanto al número, es evidente la alternancia sg./pl. referida a la 1. a persona: frente a $\operatorname{sim}($ v. 3), fui (v. 4), sum...fructa (v. 5) y data sum (v. 7), encontramos nostri...inferieis por mei...inferieis y uiximus (v. 6) por uixi cum eo; estos plurales sociativos también podrían considerarse como plurales propios, pues en el segundo ejemplo el sujeto lógico es múltiple, aunque resulta más dudoso que las inferieis del verso 2 se pudieran referir no sólo a las de Helvia Prima, sino también a las de su esposo, quién sabe si enterrado junto a ella en un modesto segundo plano.

En el juego de tiempos verbales, hay cuatro formas de perfecto que expresan matices de distinta índole. Data sum (v. 7) conlleva un claro valor resultativo ${ }^{25}$, es un perfecto de estado alcanzado, y éste es un significado gramatical reforzado por el adverbio temporal nunc, cuya presencia sólo se justifica aquí atendiendo a tal noción aspectual — «fui entregada», a resultas de lo cual «ahora me hallo en poder de...»-.

Por el contrario, las otras tres formas - fui (v.4), sum... fructa (v. 5) y víximus (v. 6) - aúnan lo aspectual con lo temporal. Respecto a lo primero, -y dado que, según formulación de $\mathrm{S}$. Mariner ${ }^{26}$, el perfecto funciona como término no marcado de la oposición perfecto (-) / imperfecto (+), bajo la noción aspectual «durativo»-, puede entenderse que estas tres formas de perfecto actualicen un uso neutro de término no marcado por marcado, significando acción que dura en el pasado, es decir, las acciones respectivas transcurren «(todo el tiempo) antes del triste adios / muerte», por tanto, hasta entonces, «(yo) era... disfrutaba... vivíamos». Sin embargo, es más fuerte su valor temporal, por el que se oponen como pasados al presente sim, siendo posible entenderlos como perfectos negativos ${ }^{27}$ : «yo fui Helvia Prima... (pero ya no soy); disfruté, vivimos... (pero ya dejé de vivir y de disfrutar)».

Dos formas nominales del verbo hacen efectiva en el texto su capacidad de funcionar como núcleos oracionales ${ }^{28}$ : el participio concertado deducta (v. 8) aporta en su oración un matiz explicativo-causal; el predicativo representado por el participio de futuro mansura (v. 7) da lugar a una construcción de índole final: «dispuesta a / con la intención de / para...quedarme», y se combina con el giro preposicional (longum) per aeum, en una iunctura peculiar que, según hace observar Bücheler, se encuentra también en Culex, 38 y en Ov. Met. V, 227, siguiendo una línea de cierta tradición literaria.

24 Degrassi contempla esta interpretación al aislar el término mediante comas, frente a otros editores.

25 Bassols, Sintaxis histórica..., II, 1, \& 84.

26 S. Mariner, «La oposición infectum / perfectum ante un análisis estructural», Actas del I Congreso español de estudios clásicos, Madrid, 1958, pp. 529-533; cf. F. Rodríguez Adrados, «Rectificaciones sobre el verbo latino», Actas del II Congreso español de estudios clásicos, Madrid, 1964, pp. 134-144.

27 Bassols, Sintaxis histórica... II, 1, \& 85.

28 Bassols, Sintaxis Latina, 1, \& 404; Ernout-Thomas, \&\& 291 y 294. 
d) Sintaxis oracional:

Se recurre en el texto al procedimiento de la periodización ${ }^{29}$, en cuanto en el corto espacio de cuatro versos encontramos una construcción oracional compleja que da lugar a un período retórico breve, pero de cierta riqueza.

Este se abre con un desarrollo adjetivo del vocativo inicial tu...uiator, por medio de una doble subordinada de relativo, en los versos 1 y 2 . La primera oración de relativo presenta una lograda disposición de palabras, que podemos representarnos como una superposición de estructuras concéntricas, gráficamente:

\begin{tabular}{|l|l|l|}
\hline tu qui & secura & spatiarus \\
\end{tabular}

donde el verbo queda en el centro exacto del verso, precedido y seguido de cinco sílabas cada vez, como si del fiel de un equilibrio fónico se tratara. Es sabido que, en el orden de palabras latino, la posición medial no es la más destacada; no obstante, se dan aquí una serie de correlaciones llamativas: el verbo se encuentra entre el adjetivo y el sustantivo de un sintagma circunstancial en dependencia; el conjunto de este predicado verbal se sitúa a su vez entre el sujeto tu qui y el vocativo referido a éste, ocupando los extremos inicial y final del verso-oración, las posiciones de mayor relieve habitualmente. Esto sugiere una intencionalidad por parte del hablante, una pura disposición estilística a la manera de tantos versos que presentan tal característica formal ${ }^{30}$, si con B. Segura ${ }^{31}$ no se pierde de vista, a la hora de justificar un orden de palabras determinado, la importancia de la función poética en un texto con evidentes pretensiones artísticas; pero también el autor pudo asignar este lugar de relevancia al verbo con afán de destacar algún valor inherente al mismo, como puede ser su contenido semántico: si se espera que la lápida sea leída con mayor probabilidad por el que va tranquilamente de paseo que por quien pasa por allí con prisas, una manera de hacer hincapié en el lexema correspondiente es otorgándole una posición especial.

Retomando la articulación del período, a las dos oraciones de relativo coordinadas entre sí mediante la partícula copulativa et les sigue una fórmula típicamente epigráfica, pero no muy usual, si quaeris quae sim, integrada por una prótasis condicional y una interrogativa indirecta dependiente de ella, y de cuyo nexo quae se desarrolla una expansión explicativo-parentética -cinis en et tosta fauilla -, lo que se denomina comma en la antigua terminología retórica. Es en el verso 4 donde aparece la apódosis y oración principal de este período condicio-

29 J. B. Hofmann - A. Szantyr, Lateinische Syntax und Stilistik, München, 1964; zweite Lieferung, pp. 732 y ss.

30 Marouzeau, op. c., pp. 319-321; nos referimos a versos del tipo Culex, 147: carmina per uarios edunt resonantia cantus; o bien Ov. Met. I, 506: sic aquilam penna fugiunt trepidante columbae; y más adelante Luc. Ph. VII, 64: pacificas saeuos tremuit Catilina securis.

31 B. Segura Ramos, «Notas sobre el orden de palabras con especial referencia al latín», Habis 10-11, 1979-1980, pp. 119-130. 
nal, que a la vez resulta ser la respuesta lógica de la interrogación anterior —en realidad, una mera convención o transición a lo que realmente se quiere decir-. Si se nos permite una adaptación pedagógica de los esquemas de Nägelsbach, en la que representamos por minúsculas latinas las oraciones subordinadas de primer grado, por minúsculas griegas las oraciones subordinadas de segundo grado; por mayúsculas las oraciones principales, así como por signos convencionales $=$, /, ( ), las relaciones de coordinación, yuxtaposición y subordinación nexual, respectivamente, el esquema de este período inicial sería el siguiente:

$$
\mathrm{a}=\mathrm{a} / \mathrm{b}(\gamma) / \gamma^{\prime} / \mathrm{A}
$$

Hasta aquí el período analizado, si bien el sentido de lo que viene a continuación incitaría a considerarlo más largo; las tres oraciones siguientes son también principales, y se articulan sintácticamente dos veces por yuxtaposición Heluia prima fui (v. 4) / coniuge sum...fructa (v. 5); ...uíximus ingenio (v. 6) / nunc data sum...(v. 7)—, y una vez por coordinación copulativa mediante la enclítica -que -coniuge sum...fructa (v. 5) = concordes víximus ingenio (v. 6)-. la yuxtaposición entre la oración nunc data sum... y las anteriores sustenta una fuerte relación adversativa, al marcarse el contraste entre la situación pasada y la actual.

\subsection{Nivel léxico - semántico.}

No resulta extraña, en un poema funerario, la reiteración de términos relacionados de una manera u otra con la idea de la muerte: inferieis (v. 2), cinis y fauilla (v. 3), obitus (v. 4), Diti (v. 7), fatali igne y aqua Stygia (v. 8); sin embargo, cada uno de ellos pertenece a distintos estratos léxicos.

El primero, inferiae, -arum es un término de la lengua religiosa, y propiamente significa «cultos consagrados a los muertos»; en ocasiones se refiere a los dona funebria, es decir, las ofrendas a los muertos hechas o presentadas en estos cultos -flores, libaciones, cabellos, etc.; cf. Verg. Geog. IV, 545: inferias Orphei Lethaea papauera mittes-; por su valor implícito de sustantivo de acción es habitual que se construya con genitivo objetivo, según decíamos más arriba. Desde el punto de vista etimológico, inferiae, -arum resulta de una sustantivación por elipsis sobre inferius, - $a$, -um, del tipo inferi, -orum sobre inferus, - $a$, -um; por otra parte, el adjetivo inferius, $-a$, - $u m$ es, como se sabe, un deverbativo en -ius sobre la raíz de fero $^{32}$. Significando por su origen «lo que se lleva al interior de», llega a relacionarse, por un fenómeno de etimología popular, con inferi, y entonces se restringe su significado a «lo que se lleva al interior del mundo de ultratumba», y adquiere el significado de «cultos en honor de los muertos»-cf. P. F. 99,26: inferiae sacrificia quae Dis Manibus inferebant-. En este contexto y en otros similares interpretan los lexicógrafos del Th. L. L., s.v. inferiae, un uso metonímico por sepulcrum, lo que hace posible distintas construcciones de lugar a dónde con este término - ad + ac.; dat. de dirección-, sobre las que volvere-

32 Leumann, \& 273, B; cf. A. Ernout - A. Meillet, Dictionnaire étymologique de la langue latine. Histoire des mots, $4^{\mathrm{e}}$ éd., París, 1979, s.v. fero. 
mos más adelante. Desde el punto de vista semántico, hay que señalar un doble desplazamiento de contenidos para el cambio semántico por metonimia, según el cual del punto de partida «ceremonia funeraria» se llega al de llegada «lugar de sepultura, tumba». Un primer momento lo representa el tomar un abstracto - ceremonia - por un concreto - los instrumentos de esa ceremonia, que son las ofrendas-; el segundo paso de la traslación metonímica consiste en entender lo contenido - los dona funebria - por el continente - el sepulcro, con todo lo que hay en él一, según explicábamos el matiz de interés que puede subsistir en este dat. de dirección, en función de su contenido.

En el verso 3 se coordinan dos términos del mismo campo semántico, cinis y fauilla, que sufren una restricción de su significado al pasar al léxico especializado de la lengua religiosa de las ceremonias fúnebres; en él presentan ambos la base semántica común de «lo que queda de los cuerpos humanos tras quemarse en la pira funeraria». Pero el significado de lengua de cinis es mucho más amplio, «restos de las cosas quemadas o consumidas»; el de fauilla es, en principio, más concreto «restos, que aún guardan calor, de las cosas quemadas». Este sema distintivo de fauilla procede seguramente de su familia etimológica, en la que se incluye el verbo foueo $^{33}$. Pese a tratarse de definiciones demasiado simplificadoras, lo cierto es que cinis tiene un uso y frecuencia mucho más amplio que los de fauilla -término marcado por uno o más rasgos sémicos privativos frente a cinis-, aunque, en ocasiones, la sinonimia se comprueba tan completa que, debido a usos neutros muy frecuentes en las estructuras léxicas, resulta bastante difícil diferenciarlos ${ }^{34}$.

En el contexto del verso 3 no hay que pensar sólo en un recurso retórico de acumulación de sinónimos, sino considerar también los hechos desde una perspectiva lingüística, viendo si ambos términos comportan o no sus respectivos valores. Según definiciones antiguas ${ }^{35}$, fauilla frente a cinis es o «partícula que arde sin fuego», es decir, «con calor», o bien «ceniza ligera, la más inconsistente», también puede ser la ceniza específicamente humana, frente a cinis, la ceniza de todo lo que ha ardido en la pira. Cualquiera de estas matizaciones es aplicable a nuestro ejemplo en menor o mayor grado; por ejemplo, si fauilla designa frente a cinis «las cenizas mínimas consumidas por el fuego», servirían para la idea de que la mujer que habla está reducida a la destrucción máxima.

33 Ernout - Meillet, op. c., s.vv. fauilla y foueo.

34 Si bien el término fauilla suele actualizar sus rasgos distintivos frente a cinis - por ejemplo, el sema «que guarda calor» se hace patente por medio del adjetivo bibulam en Verg. Aen. 6, 227: postquam collapsi cineres et flamma, quieuit, reliquias uino et bibulam lauere fauillam-, se dan otros casos en que el contenido de fauilla coincide con el de cinis, al menos en apariencia -Prop. 1, 19, 19: quae tu uiua mea possis sentire fauilla! -; en un ejemplo de Plinio se polarizan claramente los respectivos valores - Nat. 19, 19: regum inde (sc. ex lino quod ignibus non consumitur) funebres tunicae corporis fauillam ab reliquo separant cinere-. En muchos casos, fauilla podrá ser un simple doblete poético.

35 Serv. Aen. 3, 573: fauilla est deserta igni scintilla. Pelag 110: cinerem leuem, id est fauillam quam appellant. Cf. anterior ejemplo de Plinio el Viejo, en nota 34. 
El término obitus (v. 4), sustantivo de acción respecto al verbo obire, presenta aquí un uso plenamente clásico ${ }^{36}$, en el que funciona como sinónimo de mors, para lo que se exige igualmente una restricción de su valor de lengua; lo que en general significa «ida al encuentro de», se concreta en «ida al encuentro de la muerte», y por tanto, «despedida, adiós», con una presumible base eufemística, pues al recurrirse a un abstracto polisémico se evita nombrar directamente una idea tabú. Su valor semántico queda ajustado en el contexto por el atributo tristis «que produce tristeza o amargura» - el adiós triste por excelencia es el adiós definitivo, el de la muerte, que implica el no retorno-, así como por su contexto más inmediato. Usado pocas veces por Virgilio u Ovidio, quienes prefieren mors, y en segundo lugar el sinónimo poético letum, el término obitus aparece sólo 23 veces en los CLE, frente a los 356 contextos en que aparece mors $^{37}$.

El epíteto religioso Diti (v. 7) representa el correlato latino del epíteto griego $\Pi \lambda$ oú $\omega \nu$, a su vez utilizado como eufemismo del nombre del dios infernal Hades, al que se alude como el «Rico» — tesorero de los muertos o guardián de sus riquezas, dueño de los minerales y del fondo de la tierra, de donde surge toda producción vegetal - y cuyo carácter cruel e inflexible se intenta pasar por alto evocando otras cualidades benignas de esta divinidad infernal ${ }^{38}$. El epíteto pasa a la lengua latina como nombre propio Pluto, para el que se selecciona un apelativo autóctono de idéntico contenido.

El adjetivo-préstamo Stygia (v. 8), formado sobre el correspondiente nombre griego $\Sigma \tau u ́ \xi$, se encuentra ampliamente documentado en la tradición textual ${ }^{39}$, por lo que no creemos necesario detenernos sobre él.

Presentan usos metonímicos especiales los sustantivos comunes igne y aqua (v. 8), pues no designan sino la pira funeraria y la laguna o corriente Estigia, respectivamente, cuando sus significados propios son los de «fuego» y «agua», los elementos que se encuentran como semas básicos de los contenidos rogus y palus. Como veíamos en el caso de inferieis, tales metonimias se deben a desplazamientos semánticos concretos, en los que quedan implicados tanto el plano de la designación como el de la significación ${ }^{40}$ : de elemento (aqua), se pasa a designar masa o extensión originada por ese elemento (palus); de una parte se pasa a designar el todo; o incluso la causa (ignis)pasa a evocar la idea del efecto (rogus). Este uso semántico peculiar se subordina a una intencionalidad estilística, a un «extra-

36 Th. L. L. s.v.; con la noción más general de «acercamiento, comparecencia», se lee en Terencio, Turpilio y Accio; con la de «ida, desaparición o muerte», en autores más recientes, como Porcio Licino, Cicerón, Varrón, Lucrecio, César, C. Nepote, Virgilio, Propercio, Ovidio.

37 P. Colafrancesco - M. Massaro - M. L. Ricci, Concordanze dei Carmina Latina Epigraphica, Edipuglia, 1986.

38 A. Bailly, Dictionnaire Grec-Français, édition revue par L. Séchan et P. Chantraine, (n. 38), París, 1984; appendice de L. Séchan, p. 2203.

39 Paulys Real-Encyclopädie der classischen Altertumswissenschaft, begonnen von G. Wissowa, herausgegeben von W. Kroll und K. Mittelhaus, zweite Reihe /R-Z/, siebter Halbband, Stuttgart, 1931, s.v. Styx, pp. 457-465.

40 E. Coseriu, Principios de Semántica Estructural, Madrid, 1977, pp. 185 y ss. «Significado y designación a la luz de la semántica estructural». 
ñamiento» verbal que pretende presentar un concepto determinado mediante una expresión poco usual para él, permitida por la contigüidad de contenidos entre el término esperado y el que realmente aparece.

La interpretación sintáctica de ambos grupos de ablativos, tal como se recoge en nuestra traducción, se sustenta en este análisis de los hechos semánticos: mientras fatali igne se entiende como un ablativo de separación directamente relacionado con el prefijo de deducta, el segundo miembro de la correlación copulativa aqua Stygia, dada la designación a la que se refiere por metonimia, funcionaría más bien como un ablativo prosecutivo, en concurrencia con un giro preposicional per + ac. - cf. CLE 1223,5 et uos per Stygias portabit portitor undas-; por esta razón traducimos «atravesando la laguna Estigia / el agua de la Éstige», sobre la traducción literal «y por la laguna Estigia...»; por lo demás, la presencia de la serie et...et no implica necesariamente identidad de matices circunstanciales —equivalencia total que se hubiera expresado mediante la enclítica $-q u e^{41}-$, sino sólo adición de funciones, en este caso, de c. circunstanciales de lugar de dónde y por dónde. Añadamos que los adjetivos que acompañan a cada uno de estos términos refuerzan también de manera inequívoca la designado: el fatalis ignis sólo puede ser el de la pira funeraria; en aqua Stygia el adjetivo la diferencia de aqua Lethaeas, por ejemplo —cf. Verg. Aen. 6, 374-.

A medio camino entre lo léxico y lo morfológico, derigis (v. 2) es la forma originaria que comporta el significado «dirigir de un sitio a otro, desviar, volver»; pese a ello, llegará a coincidir en época clásica con otro compuesto de rego, dirigo, formado con el prefijo dis-, y que por ello significa «dirigir en distintas direcciones, dispersar». Tal coincidencia léxico-morfológica pudo verse facilitada por la homofonía entre $e$ larga (dérigo) e $i$ larga (dìrigo), ya que como vocal larga $e$ tiende a pronunciarse más cerrada de lo habitual en su timbre ${ }^{42}$, coincidiendo con la vocal palatal $i$ larga; por lo que, debido a tal equiparación en la pronunciación de la vocal inicial, se llegaría a una única forma dirigo con valor polisémico, al comportar los valores distintivos de ambos términos en colisión homofónica. Este fenómeno aún no se ha producido en el ejemplo de la inscripción.

\subsection{Nivel estilístico: recursos retóricos ${ }^{43}$.}

Ya hemos señalado algunos procedimientos que se encaminan a lograr una expresión distanciada de un nivel de lengua coloquial: disposición de verbo central en el verso 1, periodización en los dos primeros dísticos, acumulación de sinónimos combinada con aúxesis en el verso 3 -según la ley de los miembros crecientes ${ }^{44}$-, construcciones poéticas en los versos 2 y 4.

41 E. Coseriu, «Coordinación latina y coordinación románica», Actas del III Congreso español de estudios clásicos, III, Madrid, 1968, pp. 35-57; cf. Rubio, op. c., pp. 375 y ss.

42 Leumann, \& 19; Bassols, Fonética... \& 92.

43 Seguimos, para las distintas figuras localizadas en el texto, las pautas teóricas de los manuales clásicos - Hofmann-Szantyr, Marouzeau y el de H. Lausberg, Manual de Retórica literaria, Madrid, 1967-.

44 E. Lindholm, Stilistische Studien, Lund, Gleerup, 1931. 
Junto a ello, este poema funerario se abre con un apóstrofe en forma de interpelación directa y enfática al posible lector del texto in situ (uiator); sin necesidad de interjección, el énfasis apremiante para instar a la lectura lo aporta el pronombre personal $t u$, acumulado a su relativo y a la categoría de persona verbal.

En el verso 2 se produce una separación de elementos sintagmáticamente unidos - nostri...inferieis - que provoca una ambigüedad inicial sobre el elemento determinado por el genitivo, más próximo a uoltus. Pero es el sentido contextual lo que reclama la interpretación correcta, y por tanto, más que de un hipérbaton, entendemos con L. Rubio ${ }^{45}$ que se trata de una disyunción o traiectio, por lo demás repetida a lo largo del poema: v. 1, secura...mente; v. 5, coniuge...Cadmo...Scrateío; v. 6, pari...ingenio. En el verso 7 esta disposición de palabras se combina con el recurso de la anástrofe, longum...per aeum, respondiendo, como en los casos anteriores, a necesidades métricas o a una intencionalidad estilística.

En el verso 3 se suceden una serie de sílabas aliterantes: si quaeris quae sim, que repiten un esquema fónico casi uniforme; si a ello se añade el juego musical de la vocal $i$, cuatro veces en contacto con silbante, y que de por sí produce una sensación acústica de sonido agudo ${ }^{46}$, se obtiene una especial aliteración vocálica que evoca la idea más destacada en el verso, la de la ceniza inconsistente que es lo que ahora existe en lugar de la persona que existió. Esta «figura de dicción» vuelve a encontrarse en los versos 5 y 6 , donde la aliteración de velar sorda coniuge...Cadmo...Scrateío...concordesque - entona a su vez la especial solemnidad al resaltar una cualidad inherente a la matrona romana, como es la de haber sido una buena esposa ${ }^{47}$. También solemne, pero esta vez respondiendo a una idea de fatalidad, es la aliteración final data...Diti...deducta, donde se repite la dental sonora inicial, apoyada por la dental sorda interior.

Afecta a los términos Scrateío e ingenio (vv. 5 y 6) un recurso de homeoteleuton, que al producirse entre dos palabras situadas en los finales de dos versos consecutivos se convierte en rima.

Precedido de una disposición entrecruzada a distancia entre dos formas del mismo tiempo, los verbos sum...fructa (v. 5) y data...sum (v. 7), véase un quiasmo clásico fatali igne - aqua Stygia, verso 8, donde coinciden distintos recursos poéticos - peculiaridades métricas, metonimias y aliteración con miembros del verbo anterior-; representa otro más de los rasgos que confieren a este texto una conformación artificiosa.

En cuanto a la adjetivación, ésta es abundante en el texto; normalmente, los adjetivos funcionan como atributos, aportando especificaciones descriptivas - Secura...mente, obitus...tristeis, pari...ingenio, fatali...igne, aqua Stygia -, en una línea de adjetivación que recuerda a la épica; junto a esto, podrían entenderse sendos usos de adjetivo epíteto en los sintagmas tosta fauilla y longum...aeum,

46 Marouzeau, op. c., p. 31.

47 En la línea del elogium tradicional de la mujer romana suele destacarse esta idea -CIL I, 2 , 1221, 11: fído fída uiro ueixsit; CIL I 2 1570: ita leibertate illei me, hic me decoraat stola; CLE 52, 4: suom mareitum corde deilexit souo, etc.-. 
ya que el adjetivo expresa una cualidad que coincide con un rasgo inherente al contenido del sustantivo: tosta destaca el rasgo «consumido por el fuego», y ya se sabe que fauilla es lo que queda tras la acción del fuego; aeum, entendido como «tiempo en su decurso, en su fluir incesante», conlleva una noción de línea temporal a la que se ajusta bien la idea de longum.

Los autores del Th. L. L. consideran un uso por enálage en el primero de estos dos sintagmas: se aplica a fauilla una adjetivación que en realidad correspondería al cadáver consumido por las llamas, si bien no elimina ésta la interpretación anterior. Tampoco nos parece necesario entender tal traslación adjetiva en el sintagma del verso 1 -secura...mente-, según lo cual el que iría tranquilo, libre de preocupación o animadversión sería el propio caminante, pues si se considera un uso propio el significado de frase es exactamente el mismo.

Añadamos finalmente que, desde el punto de vista de la construcción, no se produce más que en el dístico final un desajuste entre verso y oración, y ello en un caso en que el verso en encabalgamiento tiene unidad de sentido ${ }^{48}$.

\section{Contenido.}

\subsection{Construcción y estructuración del poema.}

Desde el punto de vista de la construcción temática de este poema funerario, parece perfilarse algo del engranaje retórico del discurso antiguo; en los versos que comentamos cabe distinguir un exordium (A), que abarca los tres primeros versos, una narratio (B), de los versos 4 a 6 inclusive, y una conclusio (C) en los versos 7 y 8 , lo que da lugar a una estructuración casi simétrica $3(\mathrm{~A})+3(\mathrm{~B})+$ 2(C), si se tiene en cuenta que el número de versos es par, por el tipo de estrofa empleada.

En el exordium, o parte que hace entrar en materia al oyente, hemos visto ya la interpelación directa al lector ocasional, del que se precisan dos circunstancias relacionadas con la lectura del texto, así como una fórmula que sirve de transición al contenido básico de aquél, que es hacer saber quién está enterrado allí. La acción verbal del exordium transcurre en el plano del presente, y las relaciones interpersonales se dan, desde el segundo verso, entre la 2a. persona -el tú real que va de paso, con tiempo de fijar su atención en la lápida- y la 1. a, el yo del que habla por convención epigráfica desde el interior de su tumba, quizás confundido con ella y con cuanto contiene.

En la narratio se dan noticias de algunos datos personales de la interesada, incluidos en el elogio esperado de la matrona tradicional, como ya se ha dicho; todo ello se remite a la esfera del pasado, mientras algunos elementos antitéticos, contrapuestos con una disposición intencionada en los versos 3 y 4, actúan a modo de bisagras que hicieran encajar una parte con otra: sim frente a fui, en que se opone a ante, y cinis...et tosta fauilla como reverso de Heluia Prima, deslin- 
dan tajantemente el después y el antes de la muerte; en cuanto a la disposición de estos pares contrapuestos, volvemos a encontrar la figura artificiosa del quiasmo, esta vez doble y difuminado en la estructura de los versos:

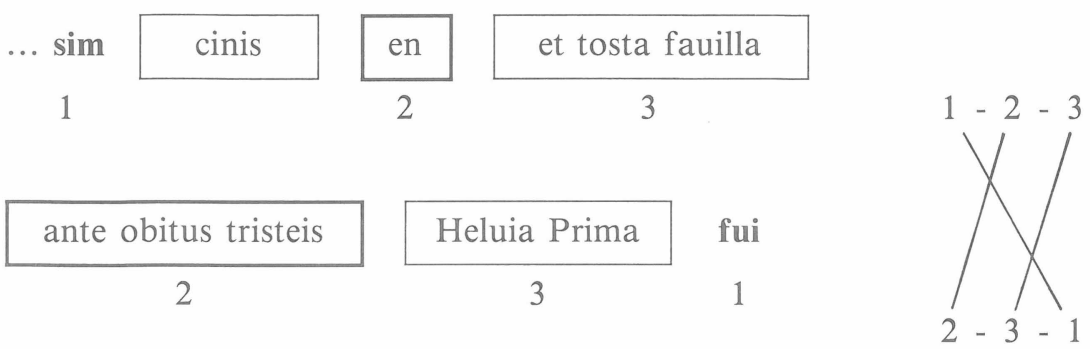

Tampoco faltan procedimientos para la articulación de la conclusio o parte final que cierra y fija el contenido global; con respecto a lo que precede, ya hemos hablado de la yuxtaposición y consecuente asíndeton que propicia una idea de fuerte contraste entre esta parte y la anterior. Mediante el adverbio temporal nunc, que se combina con un perfecto resultativo, se obtiene un elemento de retorno a la esfera del presente; hasta la cesura pentemímera tras Diti en el verso 7, parece que el poeta busca una especie de Ringkomposition: se parte del presente (A) para dar noticias del pasado (B) hasta volver al tiempo actual (C). Sin embargo, en este último dístico se da también una especie de convergencia de esferas temporales, ya implícita en el significado de aeum, y proporcionada por las formas verbales: el presente que resulta de una acción pasada, como estado alcanzado a partir de ésta (data sum), el futuro al que se proyecta la acción de mansura, y el pasado deducta, que justifica y aduce la causa del resultado actual.

El poema se cierra así con la ingenua ironía de la expresión longum mansura per aeum, que se contrarresta con el lamento fúnebre y fatalista del último verso: la mujer estará ya siempre en poder de Plutón porque ha atravesado la doble barrera del no retorno, el fuego de la pira y el agua de los infiernos.

\subsection{Conexiones del poema con otros textos epigráficos y con textos literarios.-}

Llegados a este punto del comentario, su complejidad no nos permite sino algunas observaciones particulares, que distan mucho de un estudio a fondo en la línea de trabajos ${ }^{49}$ que han venido ocupándose de la producción epigráfica latina en verso, y de su relación con la literatura; por lo demás, es evidente que

49 Pueden citarse, como títulos representativos, A. Amante, La poesía sepolcrale latina, Palermo, 1912; R. Chevallier, Épigraphie et littérature à Rome, Faenza, 1972; E. Galletier, Étude sur la poésie funéraire romaine d'après les inscriptions, Paris, 1922; A.A.V.V., Das Epigramm. Zur Geschichter einer inschriftlichen und literarischen Gattung, hrgb. von G. Pfohl, Darmstadt, 1969; W. Heraeus, «Lateinische Gedichte auf Inschriften», Hermes XLVIII, 1913, pp. 450-457; C. Hosius, «Römische Dichter auf Inschriften», Rhein. Mus. N.F.L., 1895, pp. 286-300, etc. 
ello constituiría materia autónoma difícil de incluir aquí, porque implica un análisis de otros textos además de éste.

A la vista de los hechos - se conservan varios miles de carmina epigraphica latina ${ }^{50}$-, se habla de una poesía epigráfica que, sin embargo, no llega a constituir un género, como afirma G. Sanders ${ }^{51}$.

Lo que sí sucede es que a los tituli métricos se les trasplantan elementos de géneros literarios como la laudatio funebris, la consolatio, la biografía, la elegía - cuyo contenido temático original fue la lamentación por los muertos-, etc. Ejemplificando con CLE 960, ya hemos hecho alusión a los datos biográficos contenidos en los vv. 4, 5 y 6; por otra parte, son elementos épicos los tópicos reconocibles en los versos finales: el ser entregado a Plutón y el hecho concreto de atravesar el agua de la Éstige evocan sutilmente el cuadro del mundo de ultratumba que se desarrolla, por citar un ejemplo, en el libro VI de la Eneida. En tercer lugar, la interpelación directa al lector o destinatarios, aquí como en tantas inscripciones, es un rasgo común al epígrafe y a la epístola ${ }^{52}$, y también a la pieza oratoria.

El instar a la lectura del epígrafe al posible lector que pase ante el soporte material de la inscripción, es un recurso de composición que aparece con una frecuencia muy elevada en los carmina epigraphica, tanto griegos como latinos ${ }^{53}$; pero no es el único elemento que se repite, sino que, con muchos otros, proporcionan tópicos o lugares comunes, como demuestra el excelente trabajo de B. Lier «Topica carminum sepulcralium latinorum» ${ }^{54}$. Entre los topica estudiados por Lier hay algunos que se recogen en nuestro poema:

- expresión de las virtudes del difunto, en v. 6, como CLE 52, 4: suom mareitum corde deilexit souo;

- el tema de la navegación a los infiernos, en el sintagma de ablativo prosecutivo aqua Stygia, como en CLE 1223, 5, ya citado, o CLE 1005, 9.

- la idea del regreso imposible desde allí, implícita en la expresión longum mansura per aeum, junto a CLE 1504, 11: unde fata negant redire quemquam.

Junto a estas conexiones temáticas, se dan también conexiones formales: en CLE 1050, 6 encontramos la misma construcción de dativo de dirección con el término inferiae - ut cineres patrios dederet infer(i)is-, y en CLE 1162, 4 ...misere raptus ad inferias, donde con distintas construcciones sintácticas el término designa igualmente el sepulcro, produciéndose el mismo uso por metonimia.

No faltan las fórmulas de contenido similar: en el verso 3 encontramos la expresión si quaeris quae sim como en otras inscripciones otras variantes con aná-

50 Junto a la edición de Carmina Latina Epigraphica de Bücheler, se encuentra la de E. Engström, Carmina Latina Epigraphica post editam collectionem Buechelerianam in lucem prolata, Diss. Gotoburgi, 1911, así como otras colecciones más breves, como la ya citada de S. Mariner, cf. nota 10.

51 G. Sanders, «Le dossier quantitatif de l'épigraphie latine versifiée», L'Antiquité Classique, L, 1981, pp. 707-720; cf. p. 719.

52 R. Martín - J. Gaillard, Les genres littéraires à Rome, II, París, 1981, p. 154.

53 Remitimos a diversos lugares de los CLE: 973, 980, 982, 986, 995 A, etc.

54 Este artículo se encuentra en dos números de la revista Philologus: LXII, N.F. XVI, 1903, pp. 445-477 y pp. 563-603; LXIII, N.F. XVII, 1904, pp. 54-64. 
logo significado: sei forte requiris -CLE 1076-; si quis...nomenue requirit CLE 1085 y 1086-; inuenies titulo nomina fixa meo - CLE 1111-; nomen si quaeris -CLE 63, 6 y 109, 9-; sei nomen quaeris - CLE 973, 7- y tantas otras. Desde el punto de vista del contenido, dicho esquema, con sus múltiples variantes formales, es un recurso o tópico para especificar el nombre del que se quiere recordar mediante el epitafio.

No se de extrañar que se produzcan coincidencias entre los carmina epigraphica, pues las inscripciones latinas son variadas y reiterativas a la vez; dentro de cada una de las distintas clases de inscripciones ${ }^{55}$ se distinguen varios tipos cuyos esquemas temáticos y formales se repiten con harta frecuencia. Pero si esta característica común se aplica a los carmina desde distinta perpectiva conduciría a otras derivaciones.

Un problema importante que plantean estos textos es el de si se los puede considerar o no como poéticos, materia de discusión condicionada por los criterios estéticos e ideológicos que se apliquen. Pero si se admite, con más o menos reservas, una poesía epigráfica, esos esquemas temáticos y formales que se reiteran habrán de entenderse como constantes configuradoras de uno o más géneros epigráficos, donde convergen, al parecer elementos literarios como los mencionados anteriormente.

No hay que olvidar el desarrollo paralelo - literario y epigráfico- de géneros como el epicedio y el epigrama ${ }^{56}$; éste último entronca por sus orígenes con las inscripciones, si bien su evolución literaria le lleva a una diferenciación considerable respecto a éstas ${ }^{57}$. Sin embargo, no deja de haber puntos comunes entre el epigrama literario y el epigráfico: el metro empleado, la brevedad o concisión, la interpelación al oyente, su dimensión divulgativa o social, si bien esto último sustenta una diferencia importante: mientras el epigrama literario se dirige a un amigo para una invitación, felicitación, etc. o a un enemigo para insultarlo, el epigrama inscrito se dirige a un tú cualquiera — su público es más amplio— para reclamarle su atención, informarle de algo, suscitar su emoción, advertirle o amenazarlo si tiene la intención de hacer algún daño a la inscripción.

La diferencia de destinatarios conlleva la de nivel intelectual: mientras el epigrama literario va dirigido a un círculo socio-cultural elevado, el epigrama de las inscripciones debe tener un contenido más accesible, para que todo el mundo lo entienda, en principio. Esto pudo constituir una de las razones para la diferenciación de ambos tipos de epigrama, pues el literario fue encerrándose cada vez más en sus convenciones de género.

Hasta llegar a esto, todavía pueden percibirse relaciones entre el conocido epigrama funerario de Catulo CI y CLE 960. En ambos poemas se da el mismo uso metonímico y construcciones sintácticas concurrentes del término inferiae: et nostri uoltus derigis inferieis - y vuelves el rostro / la mirada a mi sepulcro-

55 P. Batlle Huguet, Epigrafía Latina, Barcelona, 1946, pp. 65-99.

56 E. Bickel, Historia de la literatura romana, Madrid, 1982, pp. 598-599.

57 S. Piazza, L'epigramma latino I, Padova, 1898; P. Grimal, Le lyrisme à Rome, Vendôme, 1978, pp. 217 y ss. etc. 
// aduenio has miseras, frater, ad inferias - llego, hermano, ante este sepulcro desolador-; por un desplazamiento metonímico, lo que se designan no son los ritos fúnebres en honor del difunto, sino lo concreto del lugar en que se realizan. Frente a esto, en el verso 8, el término se usa para su designación habitual —estas (ofrendas) que, con triste cometido, por antigua costumbre de nuestros mayores, suelen entregarse para las exequias-. Desde el punto de vista sintáctico, en ambos casos se da una dependencia de verbo de movimiento, aunque en el carmen epigráfico se recurre a un dativo de dirección, y en el carmen catuliano a un giro preposicional, más propio de la lengua hablada, $a d+$ ac., como en CLE 1162, 4.

En los dos poemas resalta la misma pincelada de tétrico realismo: lo que hay en el sepulcro no es más que «cenizas y pavesa consumida» o «ceniza muda a la que en vano se le habla»; pero mientras Catulo se dirige a un tú que ya es materia inerte y sin vida, siguiendo aquí ${ }^{58}$ una concepción epicúrea de «nada después de la muerte» - su hermano está en el sepulcro, y no se habla en absoluto de las mansiones épicas de los muertos-, en el epígrafe puede entreverse una vida de ultratumba, desde la que Helvia Prima sigue dirigiéndose a su interlocutor.

Por otra parte, Catulo compone el poema en 1. persona, dirigiéndose a un tú que ya no puede responderle, aunque mantiene la ficción de un diálogo imposible hasta la despedida final - en realidad, es como si el poeta se condoliera consigo mismo, y, al despedirse, lo hiciera de una parte suya que se queda con su hermano, y que son las lágrimas «que manan abundantes de mi llanto fraterno», depositadas como ofrendas (inferiae) al difunto-. Por el contrario, el autor anónimo del epígrafe ajusta su función de hablante a las palabras de la difunta, a la que hace hablar en primera persona por convención epigráfica, si prescindimos de la hipótesis de que hubiera sido ella misma la que compusiera el poema en vida, dejándolo preparado para que se grabara a su muerte ${ }^{59}$.

Obsérvese, finalmente, que el epigrama catuliano y nuestro epígrafe recogen la idea «para siempre, para toda la eternidad» expresándola de distintas maneras -longum...per aeum // in perpetuum - , y que Catulo termina su lamento fúnebre con una fórmula epigráfica de despedida _...aue atque uale-, cf. CLE 1953, $1084,52-8$, etc ${ }^{60}$.

Por lo demás, ya se han destacado otras relaciones de CLE 960 con diversos lugares literarios; Bücheler señala que la iunctura mansura per aeum se encuentra en Culex 38 -memorabilis et tibi certet / gloria perpetuum lucens mansura per aeuum - y en Ovidio Met. V. 227 - quin etiam mansura dabo monimenta per

58 B. Lier, op. c., pp. 590 y ss. Por el contrario, Catulo sigue la idea de la vida de ultratumba en LXV, 5-6 y en XCVI, 5-6.

59 B. Lier, op. c., pp. 446-448.

60 De la misma manera, en algún pasaje del Corpus Tibullianum encontramos expresiones de procedencia epigráfica -Lygdami elegiae (Tib. lib. III), 2, 29-30, Lygdamus hic situs est: dolor huic et cura Neaerae / coniugis ereptae causa perire fuit. Asimismo el poema Culex finaliza con un elogium fúnebre de sabor epigráfico: parue culex pecudum custos tibi tale merenti / funeris officium uitae pro munere reddit. 
aeuum-, así como en la misma obra, libro XV, 621 -(cornua)... postibus insculpunt longum mansura per aeuum - , con variaciones en la adjetivación - perpetuum, $\varnothing$, longum-.

Bücheler pone igualmente en relación con el verso 5 otra construcción del Corpus Tibullianum, Lygdamus 3, 31 -liceat mihi / securo cara coniuge posse frui-.

Más recientemente P. Cugusi ${ }^{61}$ hace observar que Propercio, además de servir de modelo para textos epigráficos del S. I. de la era cristiana, utiliza a su vez elementos documentados en la tradición de los $C L E$, y en concreto se refiere a los versos 3 y 4 de este epígrafe que, según dicho autor, «anticipano in modo inequivocabile il luogo properziano», 2, 11, 5-6:

et tua transibit contemnens ossa uiator

nec dicet «cinis hic docta puella fuit».

Efectivamente, se da una similitud de contenidos: a la contraposición cinis en et tosta fauilla - Heluia Prima, responde en el verso properciano la contraposición cinis hic-docta puella, si bien con variaciones sintácticas.

Hay otra importantísima conexión entre los carmina epigráficos y los textos literarios, oportunamente señalada y estudiada por Lier en el trabajo mencionado: la utilización de fuentes y modelos griegos en unos y otros. En realidad, el conocido criterio de la imitación, en los cánones grecolatinos de la creación literaria, se hace aquí casi necesario: el que quiere procurarse para sí o para un allegado una sepultura con su correspondiente texto recordatorio, optará entre las primeras cosas por tomar modelos ya existentes que puedan agradarle, y que encontrará en otras lápidas; si esto sucede en cualquiera de los numerosos sitios donde podía haber una tumba griega, también valdrían como punto de referencia las inscripciones en griego.

Una última observación que no podemos dejar de hacer es la que se refiere a la dimensión socio-económica de estos carmina «de consumo», pues sus autores, anónimos artesanos de la palabra escrita, eran poetas o versificadores más o menos modestos que siempre tenían una clientela dispuesta a pagar para que le elaborasen un epitafio de su gusto, mientras para los autores de obras literarias la compensación a sus trabajos eran un glorioso renombre y la generosa protección de algún mecenas. Claro está que no todo el mundo tendría el dinero suficiente, y por eso los carmina epigraphica latina son menos abundantes de lo que podrían haber sido.

\section{Valoración crítica final.}

Terminamos el presente trabajo con la opinión de que, como a tantas otras inscripciones latinas en verso, no podría negársele una apreciación de «literario» a un poema que utiliza la palabra — y bien elaborada ciertamente- para expresar un sentimiento de sereno dolor por la propia muerte, sea éste real o fingido en

61 P. Cugusi, Aspetti letterari dei carmina latina epigraphica, Bologna, 1985, p. 187. 
el verdadero hablante; a la vez que implica algo tan humano como el deseo de no ser olvidado, manifiesto en todos los que tuvieron unas palabras grabadas sobre su tumba. Pero esto tal vez sea entender lo literario desde un punto de vista particular, cuando los hechos deben analizarse contando siempre, en la medida de lo posible, con los criterios estéticos y culturales del mundo y la época a los que pertenecen.

Desde el punto de vista de la expresión, hemos intentado señalar que hay mucho de lengua artificiosa, y de recursos tomados del latín literario, como para no situar este epígrafe en el rango de poema, y como tal sería un epigrama funerario inscrito.

En segundo lugar, hay un dato externo, la cronología del texto, que resulta importante para obtener algunas conclusiones que deben constar aquí. Si se admite, como se hace comúnmente, la datación de Bücheler —época de César-, hay que admitir también que en el epígrafe se encuentra una expresión -el ya tan repetido longum...mansura per aeum - que teóricamente sirve de modelo a dos poetas posteriores, el autor de Culex y Ovidio.

Si nos embarcamos en las dudas de Ernout acerca de esta cronología, sería más esperada la explicación inversa, es decir, que el autor del epígrafe hubiera imitado la expresión de poetas consagrados; pero entonces el poema tendría que ser posterior a Culex, al menos, o incluso al propio Ovidio, quien en Met. XV, 621 emplea exactamente la misma iunctura. Esta explicación se vería reforzada por el hecho de que, después de Virgilio, es Ovidio el poeta latino más llevado a los textos epigráficos ${ }^{62}$.

Una tercera posibilidad, que respeta la tesis más generalizada ${ }^{63}$ de que el poeta «artesano» se inspira en el poeta consagrado literariamente, y que por otro lado se adecua a la época propuesta por Bücheler, sería pensar que, en efecto, tal como muestran los usos métricos peculiares de la generación de Catulo, el epígrafe es de esta etapa, y se habría inspirado en algún poema perdido para sus logros formales más destacados, quizás de alguno de tantos escritores brillantes del 2. tercio del S. I a. JC. cuyas obras no nos han llegado.

Según esto, el epígrafe representaría una más de las fuentes para el estudio de la literatura, al recoger elementos de un modelo literario perdido; aun así, no hay que olvidar que los autores literarios tampoco desdeñaron algunos procedimientos de la lengua epigráfica, como hemos visto antes, y que también pudieron encontrar expresiones especialmente conseguidas, y adaptarlas como otros elementos del entorno cotidiano. Quizás la inscripción comentada sea uno de estos casos.

63 Cf. opera c. de Hosius, W. Heraeus y P. Cugusi —pp. 165-198-. 
